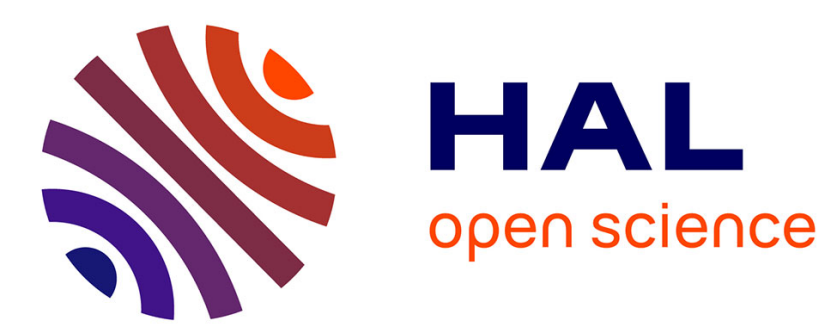

\title{
La sensibilité du pêcher au dépérissement bactérien en France : incidence de certaines caractéristiques du sol et de l'irrigation. Relations avec la nutrition
}

André Vigouroux, Jean-François Berger, Claude Bussi

\section{- To cite this version:}

André Vigouroux, Jean-François Berger, Claude Bussi. La sensibilité du pêcher au dépérissement bactérien en France: incidence de certaines caractéristiques du sol et de l'irrigation. Relations avec la nutrition. Agronomie, 1987, 7 (7), pp.483-495. hal-00885018

\section{HAL Id: hal-00885018 \\ https://hal.science/hal-00885018}

Submitted on 1 Jan 1987

HAL is a multi-disciplinary open access archive for the deposit and dissemination of scientific research documents, whether they are published or not. The documents may come from teaching and research institutions in France or abroad, or from public or private research centers.
L'archive ouverte pluridisciplinaire HAL, est destinée au dépôt et à la diffusion de documents scientifiques de niveau recherche, publiés ou non, émanant des établissements d'enseignement et de recherche français ou étrangers, des laboratoires publics ou privés. 


\title{
La sensibilité du pêcher au dépérissement bacté- rien en France : incidence de certaines caractéris- tiques du sol et de l'irrigation. Relations avec la nutrition*
}

\author{
André VIGOUROUX, Jean-François BERGER, Claude BUSSI $\left({ }^{*}\right)$
}

I.N.R.A., Laboratoire de Botanique et Pathologie végétale. ENSA, Place Viala, F 34060 Montpellier (*) I.N.R.A., SRIV, Domaine de Gotheron, F 26320 Saint-Marcel-les-Valence Pêcher et après de médiocres résultats d'amendements basiques du sol, on a essayé de vérifier, en expérimentant en grands conteneurs, que certains facteurs du sol en place et plus largement du système cultural avaient une influence prédisposante sur les arbres. Il s'agissait précisément du volume de terre exploitable par les racines, de la charge de la terre en cailloux et des modalités d'irrigation. Des conteneurs remplis de limon calcaire permettaient d'obtenir, en parallèle et à titre de référence, des pêchers tolérants à la maladie.

L'augmentation de la charge en cailloux et surtout la diminution du volume de terre disponible pour les arbres ont entraîné un accroissement de leur sensibilité estimée par contamination artificielle. Par contre, l'échelonnement et l'augmentation de l'irrigation, réalisée comme dans la pratique avec une eau calcaire, ont amené une nette réduction de la sensibilité des pêchers. En complément, un amendement calcique de la terré étudiée n'a pas modifié de façon significative le comportement des arbres.

En même temps, ces traitements entraînaient des modifications importantes de la composition minérale des arbres, en particulier en ce qui concerne le potassium et le calcium. Une corrélation a d'ailleurs été constatée entre l'importance des infections bactériennes provoquées et le potassium d'une part $(r=+0,717)$, et le calcium d'autre part $(r=-0,591)$.

Ainsi, il apparaît que certains éléments du système cultural des régions concernées par cette maladie peuvent participer à la prédisposition des pêchers au Dépérissement bactérien. Les perturbations de nutrition induites, spécialement celles au niveau du calcium et peut-être du potassium, pourraient être impliquées dans le phénomène.

Mots clés additionnels : Prunus persica, Pseudomonas syringae $p v$. persicae, milieu, techniques culturales, calcium, potassium. irrigation and relationship with tree nutrition.

After field observations in acid soil areas on which peaches are affected by Pseudomonas syringae pv. persicae and some unsuccessful basic amendment experiments, an attempt was made to determine the supposed effect of some edaphic and cultural factors on the predisposition of peach to bacterial die-back in large container culture conditions (250 1). These factors were the amount of soil colonized by the tree root system, the proportion of pebbles in the soil and the mode of irrigation. Peach trees planted in containers of calcareous loam, favouring tolerance to the disease, served as controls.

A high proportion of pebbles and above all a limited amount of soil increased the susceptibility of artificially inoculated trees. However, well spaced and increased irrigation, carried out with calcareous water as in field conditions, provided a clear cut decrease in susceptibility of the peach trees. Addition of calcium to the control soil did not really alter the behaviour of the trees.

At the same time, these treatments led to significant changes in the mineral composition of the trees, specially concerning potassium and calcium. A correlation was found between induced bacterial infections and both potassium $(r=+0.717)$ and calcium $(r=-0.591)$. Some elements of the cultural system in bacterial dieback areas may thus predispose peach trees to the disease. The observed disturbances in nutrition, specially for calcium and maybe potassium, could be involved in this phenomenon.

Additional key words : Prunus persica, Pseudomonas syringae $p v$. persicae, environmental conditions, cultural practices, calcium, potassium.

* Etude réalisée dans le cadre du groupe de travail « Dépérissement Bactérien du Pêcher » encouragé par le Fond National des Calamités Agricoles, l'Etablissement Public Régional/Rhônes-Alpes et le Ministère de l'Agriculture. 


\section{INTRODUCTION}

Parmi les diverses bactérioses qui affectent les arbres fruitiers à noyau en France, le Dépérissement Bactérien du Pêcher, provoqué par Pseudomonas syringae pv. persicae (PRUNIER, LUISETTI, GARDAN) est probablement la plus grave par l'intensité et la permanence de ses dégâts.

Pourtant, après une inquiétante période d'extension géographique (PrUNIER et al., 1976), à partir de sa zone d'apparition sur le plateau du Moyen Vivarais (VIGOUROUX, 1968), la maladie semble connaître, depuis quelques années, une certaine stabilisation.

Une comparaison de son aire d'extension actuelle avec la carte géologique du sud-est de la France suggère une restriction de la maladie à des régions à sols généralement acides. Aux U.S.A., des observations similaires ont été réalisées à propos d'une bactériose voisine (WEAVER \& WEHUNT, 1975).

En fait, dès sa progression géographique, cette affection s'était montrée nettement plus grave dans les vergers implantés sur certains sols, en particulier ceux formés sur arène granitique ou sur alluvions anciennes des terrasses du Rhône (diluvium alpin). Des expérimentations à l'aide de jeunes pêchers cultivés en conteneurs avaient permis de confirmer que la terre de ces sols, opposée à un limon calcaire, constituait en ellemême un facteur prédisposant (VIGOUROuX \& HUGUET, 1977, 1980).

Des essais d'amendements basiques dans les mêmes conditions (VIGOUROUX \& HUGUET, 1977, 1980) n'ont cependant fourni que des améliorations de résistance assez partielles. De plus, une expérimentation en plein champ, dans des conditions climatiques il est vrai particulièrement favorables à la maladie (VIGOUROUX, 1979), n'a pas donné de résultats appréciables (VIGouroux et al., 1982).

Ces éléments, ajoutés à diverses observations de terrains, suggéraient qu'en complément des caractéristiques essentiellement chimiques et minérales de la terre envisagées jusque là, devait être pris en compte tout le fonctionnement du système sol-plante.

Pour dégager quelques voies d'étude, une campagne d'observations de profils de sols de vergers fut entreprise*, en opposant sols de plantations indemnes en zones calcaires et sols formés sur arène granitique ou sur alluvions caillouteuses anciennes. Une soixantaine de parcelles bien typées ont été analysées.

Indépendamment des notions de $\mathrm{pH}$, cette prospection nous a permis de constater que les sols d'arène et ceux formés sur alluvions anciennes, bien que d'origine et de nature très différentes, s'opposaient de façon commune aux sols calcaires par une texture beaucoup plus grossière et une profondeur exploitée nettement plus faible. Cette dernière caractéristique était d'ailleurs souvent accentuée par des phénomènes d'hétérogénéité marquée de la zone ameublie, induits par la réalisation du labour de défoncement : des remontées d'horizon $B$ de nature plus argileuse constituaient autant de volumes de terre non ou très peu exploités par les racines de pêchers (cf. horizon H5 de MANICHON, 1982). En outre, le niveau non ameubli, sous la «semelle » de défoncement, était beaucoup moins colonisé par les racines qu'en sol calcaire.

\footnotetext{
* avec les conseils, sur le terrain, de MM. G. Callot et M. BorNAND, de la Station de Science du Sol, I.N.R.A., Montpellier.
}

Ainsi, la réserve en eau utile de ces sols apparaissait très limitée et la difficulté de leur exploration par le système radiculaire abaissait encore le niveau de disponibilité des ressources quelles qu'elles puissent être (GRAS, 1962 ; MAERTENS, 1964 ; HENIN et al., 1969 ; MAERTENS, communication personnelle).

En parallèle, les zones les plus affectées par la maladie dans les parcelles correspondaient toujours aux parties spécialement caillouteuses et à texture grossière, à moins qu'il ne s'agisse des parties hautes pour les vergers en pente.

En complément, on pouvait constater que les irrigations de ces plantations malades, lorsqu'il y en avait, étaient réalisées par aspersion sous forme d'apports importants (souvent de l'ordre de $60 \mathrm{~mm}$ ) et espacés.

Ces divers éléments, ajoutés aux niveaux relativement faibles des bases de ces sols à capacité d'échange cationique (CEC) limitée, nous ont semblé susceptibles d'entraîner, entre autres, une alimentation hydrique et minérale suffisamment déficiente pour initier une sensibilité anormale des arbres à l'infection bactérienne.

Divers auteurs avaient déjà souligné l'incidence directe d'un stress hydrique sur le développement de plusieurs affections, provoquées généralement par des champignons agents de chancre d'écorce (BLOOMBERG, 1962 ; BIER, 1964 ; BERTRAND et al., 1976 ; SCHOENWEISS, 1981 ; APPEL \& STIPES, 1984) mais une observation analogue à propos d'une bactériose a aussi été rapportée chez le Noisetier (MOORE et al., 1974).

Pour le cas qui nous occupe, le décalage entre l'époque d'instauration du déficit hydrique, qui se produit évidemment en été, et la période du développement des infections bactériennes, qui se situe en hiver, suggère plutôt une relation indirecte avec des mécanismes d'intervention a priori différents.

En partant de nos observations de terrain, nous avons donc cherché, d'une part, à vérifier que les caractéristiques notées dans les profils des sols prédisposants constituaient bien des éléments facteurs de prédisposition, et d'autre part, qu'une amélioration du mode d'irrigation, compensant peut être l'effet de ces éléments, permettrait de réduire la réceptivité des pêchers à l'infection bactérienne.

Pour cela, nous avons essayé de recréer en grands conteneurs des variantes édaphiques simples analogues à celles observées au champ, ainsi que des régimes d'irrigation tranchés. La sensibilité de pêchers cultivés dans ces conteneurs a été comparée par contamination artificielle. Enfin, dans le but d'entamer une approche des mécanismes physiologiques en jeu, nous avons réalisé des analyses minérales des rameaux de ces arbres et le fonctionnement hydrique a été suivi pendant toute la saison de végétation qui a précédé les inoculations.

\section{MATÉRIEL ET MÉTHODES}

\section{A. Dispositif de culture}

Le principe était de travailler sur de jeunes arbres cultivés individuellement, durant un temps assez court et en conteneurs suffisamment grands, pour que l'effet de confinement du système radiculaire soit 
limité sinon négligeable, tout en ayant la possibilité de réaliser diverses modifications simples du substrat de façon assez bien contrôlée.

Pour cela, nous avons cultivé des scions* de pêcher de la variété J. H. HALE, greffés sur GF 305, durant un an dans des conteneurs de $250 \mathrm{l}$.

Nous avons réalisé un arrosage bien réparti sur toute la surface du substrat, le débit étant de l'ordre de 15 litres/heure. Une protection contre la pluie permettait de contrôler complètement le rythme et les quantités d'eau fournies aux arbres.

Afin de pouvoir évaluer les quantités d'eau consommées par chaque arbre, on pouvait peser commodément chaque bac avec une précision de $200 \mathrm{~g}$.

Les bacs étaient disposés selon 2 lignes parallèles, 2 réseaux distincts de tuyaux permettant des régimes d'irrigation différents pour des arbres répartis en mélange. L'ensemble était protégé des contaminations bactériennes sauvages extérieures par un tunnel de grillage du genre moustiquaire en polyéthylène translucide. Ce matériau n'entraîne qu'une légère augmentation des températures maximales $\left(1\right.$ à $\left.2^{\circ} \mathrm{C}\right)$ mais absorbe environ 40 p. 100 du rayonnement global (mesures par l'équipe de M. SCHOCH, station de Bioclimatologie I.N.R.A.-Montfavet).

Le dispositif, implanté sur le domaine I.N.R.A.SRIV de Gotheron près de Valence, était ainsi placé dans les conditions climatiques favorables à la maladie.

Le déroulement de l'expérimentation a suivi le cours normal d'une culture en verger avec remplissage des bacs et plantation des arbres pendant l'hiver 19821983 et végétation durant une année. Les inoculations et prélèvements pour analyse minérale ont été réalisés l'hiver suivant (1983-1984), les infections bactériennes se stabilisant en fin d'hiver.

* Scion : jeune arbre qui a été greffé en pépinière, s'y est développé un an et se trouve prêt à la plantation en verger.

\section{B. Traitements réalisés}

Concrètement, en partant d'un substrat de base prédisposant et d'un régime hydrique banal dans la région, l'expérimentation a cherché à estimer l'influence du faible volume de sol exploré par les racines, l'effet d'une forte teneur en cailloux et celui d'une amélioration des conditions d'irrigation. En complément, on a aussi étudié les conséquences d'un amendement à base de chaux, pour rapprocher les résultats de cette expérimentation de ceux de nos essais antérieurs (cités en introduction). Enfin, pour disposer d'une référence permettant de situer de façon plus absolue le niveau des améliorations de résistance éventuellement obtenues, une série de bacs a été remplie de limon argilo-calcaire. Les vergers sur de tels limons sont en effet pratiquement indemnes de maladie, quel que soit le régime d'irrigation pratiqué.

On a utilisé comme substrat de base prédisposant une terre correspondant à la terrasse du Rhône de l'époque de RISS (sol fersiallitique sans réserve calcique, d'après BORNAND, 1968). Seul a été prélevé l'horizon supérieur sablo-limoneux et caillouteux où, dans les vergers, les racines de pêcher restent confinées à $90 \mathrm{p} .100$. On appelera commodément ce substrat " diluvium». La terre argilo-calcaire provenait des alluvions récentes du Rhône, près de Loriol (26). Les caractéristiques physico-chimiques des 2 types de terre figurent au tableau 1. Il faut souligner que la fraction supérieure à $2 \mathrm{~mm}$, composée de graviers et cailloux est réduite à moins de 10 p. 100 du total pour le limon alors qu'elle est de l'ordre de 50 p. 100 et plus pour la terre d'alluvions anciennes.

Le régime d'irrigation de référence s'inspirait de celui pratiqué dans tous les vergers de la région : il consistait en une saturation soignée de la capacité de rétention en eau du substrat (vérifié par des pesées successives après drainage) suivi de son dessèchement progressif par la consommation de l'eau par les

Caractéristiques physiques et chimiques des deux types de terres utilisées. Physical and chemical characteristics of the two types of soil used.

\begin{tabular}{|c|c|c|}
\hline Eléments analysés & Limon calcaire & $\begin{array}{c}\text { Terre } \\
\text { d'alluvions anciennes }\end{array}$ \\
\hline \multicolumn{3}{|l|}{ Granulométrie sans decal. 5 fractions $\ldots \ldots \ldots \ldots \ldots \ldots \ldots \ldots \ldots \ldots \ldots \ldots \ldots \ldots$} \\
\hline - argile & 247 & 100 \\
\hline - limon fin & 299 & 154 \\
\hline - limon grossier & 200 & 151 \\
\hline - sable fin & 198 & 266 \\
\hline — sable grossier & 56 & 329 \\
\hline Fraction supérieure à $2 \mathrm{~mm}$ & 9 & 45 \\
\hline $\mathrm{pH}$ & 8,2 & 5,7 \\
\hline$C=$ carbone organique (méthode Anne 1945) . & 14,8 & 7,2 \\
\hline matières organiques $(=C \times 1,72) \ldots$ & 25,4 & 12,3 \\
\hline 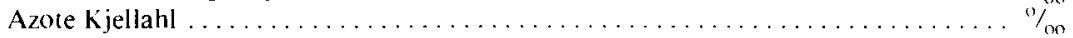 & 1,8 & 0,74 \\
\hline Rapport carbone organique (Anne)/Azote Kjeldahl & 8,22 & 9,72 \\
\hline Calcaire total $\ldots \ldots \ldots \ldots \ldots \ldots \ldots \ldots \ldots \ldots \ldots \ldots$ & 364 & 0 \\
\hline Acide phosphorique Joret Hebert . & 0,07 & 0,05 \\
\hline Capacité d'échange méthode de Metson $\ldots \ldots \ldots \ldots \ldots \ldots \ldots \ldots \ldots \ldots$.EQ. $\%$ & 10,5 & 4,2 \\
\hline Calcium échangeable $\ldots \ldots \ldots \ldots \ldots \ldots \ldots \ldots \ldots \ldots \ldots \ldots \ldots \ldots$ & 35,4 & 3,1 \\
\hline Magnésium échangeable $\ldots \ldots \ldots \ldots \ldots \ldots \ldots \ldots \ldots \ldots \ldots \ldots \ldots \ldots \ldots \ldots \ldots$ & 0,86 & 0,17 \\
\hline 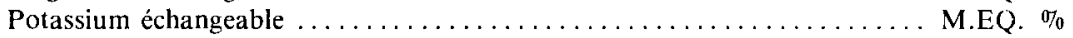 & 0,185 & 0,276 \\
\hline Manganèse méthode Bittel . . & 0,135 & 0,159 \\
\hline Bore soluble eau bouillante $\ldots \ldots \ldots \ldots \ldots \ldots \ldots \ldots \ldots \ldots \ldots \ldots \ldots \ldots$ & 0,28 & 0,19 \\
\hline Zinc extractible HCL $0,2 \mathrm{~N}$. . & 1,330 & 2,870 \\
\hline
\end{tabular}


pêchers sous forme d'évapo-transpiration ; ceci jusqu'à un point de contrainte hydrique assez élevé ; ce point était repéré par un début de mollissement des feuilles perceptible en fin de matinée, confirmé par des mesures de potentiel de sève. Le substrat était alors saturé à nouveau complètement. A souligner que les observations étaient réalisées sur le témoin de référence, le déclenchement de la nouvelle saturation étant étendu alors à tous les traitements simultanément.

On a ainsi obtenu plusieurs cycles de dessèchement au cours de l'été.

Plus précisément, les traitements réalisés ont été les suivants :

\section{Diluvium témoin (en abrégé, DT)}

On a rempli les bacs avec le substrat de base à raison de $370 \mathrm{~kg}$ de terre par bac.

On leur a appliqué le régime d'irrigation de référence à caractère périodique décrit ci-dessus.

\section{Diluvium volume réduit (DVR)}

Pour se rapprocher des conditions d'un faible volume de sol exploré par les racines, on a utilisé des bacs d'une contenance réduite que l'on a rempli de $170 \mathrm{~kg}$ de diluvium de base (cette quantité était en outre celle utilisée dans nos précédents essais).

L'arrosage était périodique, identique à celui du témoin.

\section{Diluvium + cailloux (DC)}

Pour élever la proportion de cailloux dans le diluvium de base, on y a apporté en plus, dans la proportion de 30 p. 100 en poids, des galets de nature granitique et compacts. La quantité de substrat par bac restait fixé à $370 \mathrm{~kg}$.

L'arrosage était périodique, identique à celui du témoin.

\section{Diluvium régulièrement irrigué (DRI)}

Les bacs, remplis de $370 \mathrm{~kg}$ du diluvium de base comme les bacs témoins ont, par contre, subi une irrigation permettant de maintenir constamment le substrat aux 4/5 environ de sa capacité au champ. En pratique, on apportait chaque jour ou tous les 2 jours la quantité d'eau nécessaire pour maintenir un poids constant déterminé au préalable ; (quantité correspondant donc à la quantité d'eau évaporée pendant ce laps de temps).

\section{Diluvium amendé (DA)}

Toujours pour un total de $370 \mathrm{~kg}$ de substrat par bac, le diluvium de base a été amendé par mélange avec de la chaux éteinte à raison de $1 \mathrm{~g}$ de $\mathrm{CaO}$ par $\mathrm{kg}$ de terre, ce qui correspond à environ 4,2 de chaux éteinte à l'hectare. C'était la proportion utilisée dans nos essais antérieurs.

L'irrigation était périodique, identique à celle du témoin.

\section{Limon argilo-calcaire de référence (LAC)}

Les bacs ont été remplis avec le limon argilocalcaire décrit plus haut. Comme la notion de volume était importante (la profondeur des sols était envisagée comme facteur de prédisposition), on a utilisé des bacs identiques à ceux du témoin, contenant donc environ $250 \mathrm{l}$ de terre, mais cela correspondait à $320 \mathrm{~kg}$ de limon. La faible teneur en cailloux de ce type de terre réduit en effet sa densité par rapport au témoin très caillouteux.

L'irrigation était périodique, identique à celle du témoin.

Chaque traitement portait sur 10 arbres analysés individuellement et représentant autant de répétitions. Puisqu'il s'agissait de comparer les moyennes de ces traitements en se référant à 2 types de témoins (traitements 1 et 6) et en situant les moyennes entre elles, l'analyse statistique a été réalisée à l'aide du test de comparaison de moyenne de NEWMAN et KEULS.

\section{Modalités d'irrigation}

Les régimes d'irrigation différenciés n'ont pu être appliqués et suivis avec précision que de mi-juillet à fin septembre. Avant et après, et selon un rythme variable avec le climat, tous les bacs recevaient une dose d'eau identique - celle propre à saturer la capacité de rétention en eau du substrat des témoins afin d'entretenir chez ces derniers un niveau de turgescence à peu près normale. Pour les arbres végétant en volume réduit, une partie de cette eau était perdue par drainage, d'où un certain déficit hydrique qui s'est traduit par un développement un peu réduit. A l'opposé, les arbres sur limon n'ont pas bénéficié de tout l'avantage de la plus grande capacité de rétention de ce type de terre : à volume égal, la réserve potentielle qu'elle constituait n'était que partiellement remplie quand le substrat témoin était saturé. Ainsi les capacités de rétention en eau des divers substrats n'ont surtout joué que pendant la période d'analyse (c'était l'époque des consommations maximum) et, à ce moment, les écarts entre le développement ou la masse de feuillage des arbres, selon les traitements, étaient relativement limités, au moins à volume de substrat identique. Les comparaisons de fonctionnement hydrique des arbres s'en trouvaient ainsi plus justifiées.

Compte tenu de la différence de volume de substrat, les arbres cultivés dans les petits bacs ont subi vers la fin de plusieurs cycles de dessèchement des contraintes hydriques extrêmement élevées. Pour éviter que celles-ci ne soient excessives, on leur a ajouté chaque fois et vers la fin de chaque cycle 1 ou 2 litres d'eau en appoint.

Toutes ces irrigations ont été réalisées avec l'eau du réseau municipal, qui, à l'analyse, s'est révélée assez fortement calcaire $\left(30^{\circ} \mathrm{H}\right.$ environ).

\section{Suivi du fonctionnement hydrique des arbres}

On a comparé le fonctionnement hydrique des arbres selon les divers traitements en suivant par pesées échelonnées des bacs, en moyenne tous les 2 jours, l'évolution des quantités d'eau évapotranspirées par chaque arbre.

On a aussi suivi les variations du potentiel de sève des feuilles en mesurant celui-ci à l'aide d'une chambre à pression (SCHOLANDER et al., 1965; BOYER, 
1967 ; TURNER, 1981). On s'est surtout attaché à l'analyse du potentiel dit "de base " obtenu en fin de nuit. A ce moment-là, le potentiel est en effet équilibré au niveau des diverses parties de l'arbre et apparaît, pour l'essentiel, influencé par la disponibilité de l'eau au niveau du substrat (KLEEPER, 1968 ; AUSSENAC \& GRANIER, 1978). En outre, l'homogénéité des contraintes entre feuilles dans ces conditions permettait d'obtenir une précision satisfaisante avec 3 mesures de feuille par arbre seulement.

La mesure du potentiel hydrique de tige, reconnu plus sensible au dessèchement du sol (GARNIER, 1985), n'a pu être appliquée sur de très jeunes arbres du fait de son caractère destructif important.

Les mesures du potentiel de sève n'étaient mises en œuvre que plusieurs jours après le début de chaque cycle de dessèchement car, les premiers jours, l'eau est facilement disponible dans tous les substrats et les potentiels plus ou moins identiques.

\section{E. Estimation des conséquences des traitements sur la nutrition des arbres}

Comme autre critère de la répercussion des traitements sur la physiologie des arbres, nous avons estimé leur niveau d'alimentation minérale à travers l'analyse de la composition de l'écorce de leurs rameaux (c'est la zone de tissus où se développe spécialement la bactérie).

Les prélèvements ont été réalisés en hiver, en février, au moment de l'évolution de la maladie. Sur chaque arbre, on a prélevé 12 anticipés $\left({ }^{1}\right)$ d'environ $20 \mathrm{~cm}$, bien répartis sur la couronne et de façon comparable entre traitements. Compte tenu du développement un peu moindre des arbres cultivés en petit bac, il a été impossible d'échantillonner correctement les anticipés sur chaque arbre, ce qui est important compte tenu de l'hétérogénéité de la répartition de certains ions (CumMINGS, 1973). Dans le cas de ce traitement, nous avons donc regroupé les individus proches par paires, en prélevant sur chaque arbre 8 anticipés, de façon à obtenir pour chaque paire un échantillon suffisant de 16 rameaux à analyser.

Dans tous les cas, rapidement enlevés, les lambeaux d'écorce ont été lyophilisés puis réduits en poudre pour être envoyés en récipients étanches, au laboratoire d'analyses végétales de l'I.N.R.A. à Bordeaux.

\section{F. Estimation de la sensibilité comparée des pêchers}

Le critère de sensibilité généralement choisi (VIGOUROUX, 1968 ; PRUNIER et al., 1973) est la longueur des lésions obtenues sur rameau d'un an après inoculation artificielle sur blessure. La technique habituelle d'inoculation par piqûre en automne n'a pas fourni d'infections appréciables du fait des conditions anormalement douces (VIGOUROUX, 1979) du début de l'hiver 1983-1984. On a donc du refaire des inocula-

(1) Anticipé : petit rameau issu d'un bourgeon qui se développe sur une pousse vigoureuse en cours d'été et pendant l'allongement même de cette pousse (et non au printemps suivant). Type d'organe spécialement fréquent chez le Pêcher et de longueur variable selon sa date d'apparition ; appelé aussi pousse syleptique. tions vers le milieu de janvier en utilisant une méthode plus sévère car, à cette époque, les pêchers sont moins réceptifs (VIgOUROUX, 1968 ; PRUNIER et al., 1973).

Sur rameau d'un an, à environ $15 \mathrm{~cm}$ de l'extrémité, on a arasé un bourgeon et le coussinet pétiolaire sous-jacent puis on a badigeonné la plaie obtenue avec la pointe d'un fin pinceau trempé dans une suspension de bactéries dosée à 10 germes par $\mathrm{ml}$.

Chaque arbre a reçu 5 inoculations de ce type. Le développement des lésions a été suivi durant le mois de mars puis mesuré définitivement après stabilisation début avril. On a pris en compte la moyenne des 5 lésions par arbre.

\section{RÉSULTATS}

\section{A. Fonctionnement hydrique des arbres durant la sai- son végétative}

Les différents traitements appliqués aux pêchers pendant la période d'analyse ont entraîné des écarts importants entre les quantités d'eau évapo-transpirées par les arbres.

A titre d'exemple, on a illustré par les courbes de la figure 1 l'évolution comparée, en quantités cumulées, de l'eau évapo-transpirée en moyenne par chaque arbre au cours des $2^{\mathrm{e}}$ et $3^{\mathrm{e}}$ séquences de dessèchement (3/8 au $18 / 8$ et $19 / 8$ au $7 / 9)$. Des courbes d'allure et de disposition analogues ont été obtenues pour les autres séquences.
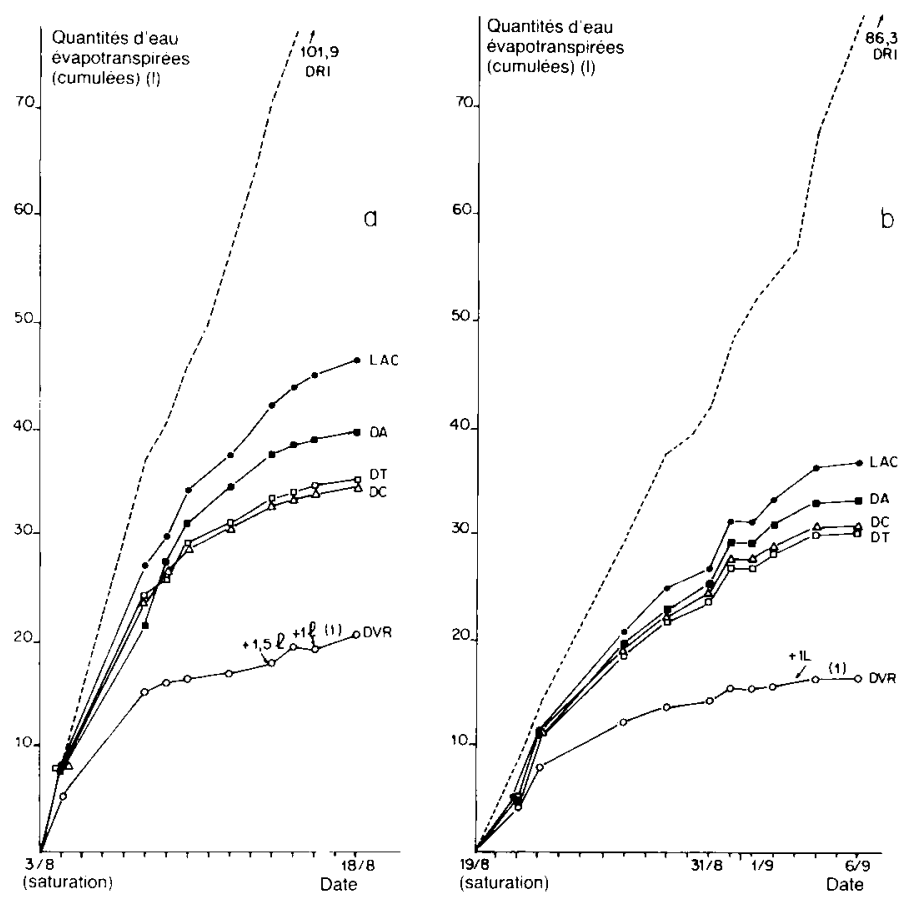

(1) Apporis d'eau « de survie ».

Figure 1

Exemple, pour deux périodes de l'été, de l'évolution comparée des quantités d'eau évapotranspirées par les pêchers selon les traitements.

Amount of water used by peach trees in two summer periods, according to treatments. 
TABLEAU 2

Quantités moyennes d'eau évapotranspirée par un arbre selon les traitements et les périodes de végétation. Mean amount of water used by a peach tree according to treatment and growth period.

\begin{tabular}{|c|c|c|c|c|c|c|c|c|c|c|c|c|c|}
\hline \multirow{3}{*}{ Draitements } & \multicolumn{10}{|c|}{ Période des séquences de déssèchement de l'été } & \multirow{3}{*}{$\begin{array}{c}\text { Période avant } \\
\text { et après les } \\
\text { séquences de } \\
\text { déssèchement }\end{array}$} & \multirow{2}{*}{\multicolumn{2}{|c|}{$\begin{array}{c}\text { Saison } \\
\text { complète } \\
\text { (Total 1983) }\end{array}$}} \\
\hline & \multicolumn{2}{|c|}{$\begin{array}{l}\text { Séquence du } \\
27 / 7 \text { au } 1 / 8 \text { (1) }\end{array}$} & \multicolumn{2}{|c|}{$\begin{array}{l}\text { Séquence du } \\
3 / 8 \text { au } 18 / 8\end{array}$} & \multicolumn{2}{|c|}{$\begin{array}{l}\text { Séquence du } \\
19 / 8 \text { au } 6 / 9\end{array}$} & \multicolumn{2}{|c|}{$\begin{array}{l}\text { Séquence du } \\
8 / 9 \text { au } 28 / 9\end{array}$} & \multicolumn{2}{|l|}{ Total } & & & \\
\hline & $\begin{array}{c}26,6\left(^{2}\right) \\
(2,25)\end{array}$ & $100\left({ }^{3}\right)$ & $\begin{array}{r}35,7 \\
(2,90)\end{array}$ & 100 & $\begin{array}{c}31,0 \\
(2,19)\end{array}$ & 100 & $\begin{array}{c}32,8 \\
(2,54)\end{array}$ & 100 & $126,1 \mathrm{~B}\left({ }^{5}\right)$ & 100 & & 276,1 & 100 \\
\hline Diluv. Vol. Réduit : DVR & $\begin{array}{c}15,8 \\
(0,72)\end{array}$ & 59,4 & $\begin{array}{r}18,4 \\
(1,07)\end{array}$ & 51,5 & $\begin{array}{c}17,4 \\
(0,81)\end{array}$ & 56,1 & $\begin{array}{c}18,2 \\
(0,97)\end{array}$ & 55,5 & $69,8 \mathrm{~A}$ & 55,3 & 110 & 179,8 & 65,1 \\
\hline Diluvium + Cailloux : DC & $\begin{array}{l}26,9 \\
(2,83)\end{array}$ & 101,1 & $\begin{array}{r}34,9 \\
(2,08)\end{array}$ & 97,7 & $\begin{array}{c}31,7 \\
(2,13)\end{array}$ & 102,2 & $\begin{array}{l}33,1 \\
(2,71)\end{array}$ & 100,9 & $126,6 \mathrm{~B}$ & 100,4 & 150 & 276,6 & 100,2 \\
\hline Diluv. Régul' Irrig. : DRI & $\begin{array}{c}45,8 \\
(2,83)\end{array}$ & 172,2 & $\begin{array}{l}101,9 \\
(3,01)\end{array}$ & 285,4 & $\begin{array}{c}79,0 \\
(3,19)\end{array}$ & 254,8 & $\begin{array}{c}86,3 \\
(3,11)\end{array}$ & 263,1 & $313,0 \mathrm{E}$ & 248,2 & 150 & 463,0 & 167,7 \\
\hline Diluv. Amendé : DA & $\begin{array}{l}29,1 \\
(1,58)\end{array}$ & 109,4 & $\begin{array}{r}40,3 \\
(2,98)\end{array}$ & 112,9 & $\begin{array}{c}34,1 \\
(1,94)\end{array}$ & 110,0 & $\begin{array}{c}34,9 \\
(2,52)\end{array}$ & 106,4 & $138,4 \mathrm{C}$ & 109,7 & 150 & 238,4 & 104,4 \\
\hline Limon Argilo-Calcaire : LAC & $\begin{array}{l}33,9 \\
(2,20)\end{array}$ & 127 & $\begin{array}{r}46,9 \\
(3,54)\end{array}$ & 131 & $\begin{array}{c}37,5 \\
(2,41)\end{array}$ & 121 & $\begin{array}{c}38,4 \\
(2,21)\end{array}$ & 117 & $156,7 \mathrm{D}$ & 124,0 & 150 & 306,7 & 111,1 \\
\hline
\end{tabular}

$\left({ }^{1}\right)$ Séquence d'essai, écourtée. $\left({ }^{2}\right)$ Quantités en litres. $\left({ }^{3}\right)$ Indices de comparaison au témoin. $\left({ }^{4}\right)$ Ecart-type pour 10 arbres. $\left({ }^{5}\right)$ Seuls les chiffres suivis d'une lettre différente peuvent être considérés comme significativement différentes, au seuil de $5 \%$. $(6$ ) Quantités estimées.

En outre, on a regroupé dans le tableau 2 les quantités d'eau totales consommées en moyenne par chaque arbre et par traitement au cours des différents cycles de dessèchement de l'été et des diverses périodes de la saison de végétation.

En se limitant à la période d'étude et en analysant les mesures de consommation individuelles, on peut classer les 6 traitements en 5 groupes significativement distincts au seuil de 5 p. 100 :

$$
\text { DVR - (DT.DC) - DA - LAC - DRI. }
$$

Les mesures de potentiel hydrique ont aussi permis de confirmer que les traitements ont imposé aux arbres des contraintes hydriques assez différentes. Les écarts sont visualisés par exemple par les courbes que l'on a élaborées à l'aide des mesures réalisées lors des $2^{\mathrm{e}}$ et $3^{\mathrm{e}}$ séquences (fig. 2) (homologues des courbes de consommation d'eau analysées ci-dessus).

Les mesures fournies par la chambre à pression correspondent à un potentiel de sève qui est, strictement, la traduction d'une dépression. Nous avons préféré l'interpréter et l'exprimer comme sa conséquence, c'est-à-dire une contrainte plus ou moins intense à laquelle l'arbre est soumis ; c'est pourquoi nous avons dressé des graphiques avec ordonnées positives illustrant plus concrètement l'augmentation de cette contrainte en fonction du dessèchement du substrat.

Les écarts entre traitements sont plus ou moins marqués selon l'importance de l'E.T.P.

Le traitement Diluvium Volume Réduit (DVR) se distingue évidemment de façon très particulière par un accroissement très rapide de la contrainte hydrique. On note, en outre, les chutes ponctuelles brutales, liées aux additions d'eau « de survie».

\section{B. Composition minérale des tissus corticaux des rameaux}

Les divers traitements ont aussi induit des différences importantes dans la composition des écorces des rameaux des pêchers traités.

En nous limitant aux principaux cations (les autres éléments analysables, l'azote en particulier, n'ayant
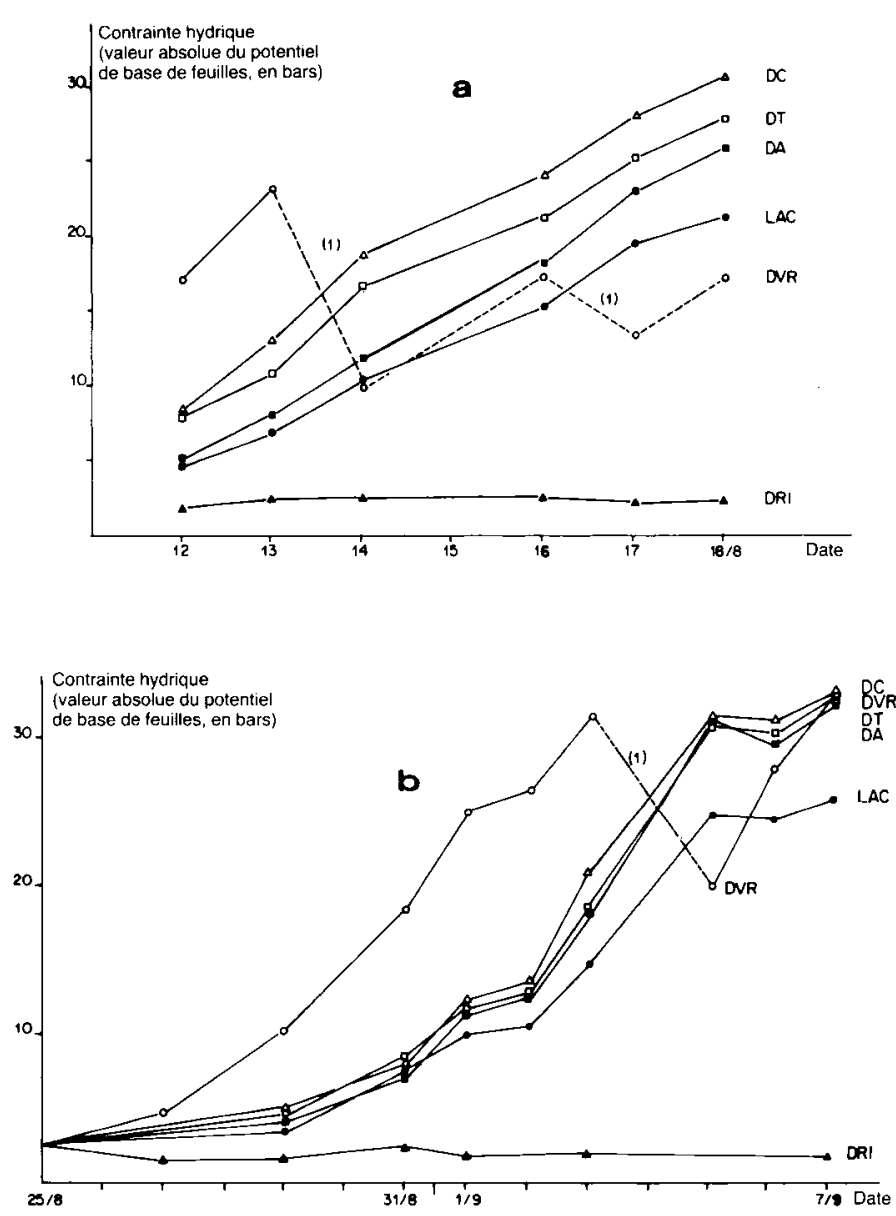

(1) Apports d'eau « de survie ».

Figure 2

Exemple pour deux périodes de l'été, de l'évolution comparée de la contrainte hydrique subie par les pêchers selon les traitements.

Water stress suffered by peach trees in two summer periods, according to treatments.

montré aucun écart notable) nous avons regroupé les résultats des analyses par traitement dans le tableau 3.

Dans le cas du traitement "volume réduit ", la moyenne présentée n'est issue que d'un effectif de 5 
TABLEAU 3

Teneur moyenne par arbre en cations des écorces de rameau des pêchers soumis aux traitements.

Mean cation content, per tree, of the twig bark of treated peach trees.

\begin{tabular}{|c|c|c|c|}
\hline Traitements Cations $\%$ & K & $\mathrm{Ca}$ & $\mathrm{Mg}$ \\
\hline Diluvium Témoin : DT & $0,959 \mathrm{C}(1)$ & $2,643 \mathrm{~A}\left({ }^{1}\right)$ & $0,108 \mathrm{~A}\left({ }^{(}\right)$ \\
\hline Dil. Vol. Réduit : DVR & $1,028\left({ }^{2}\right)$ & $2,008\left(^{(2)}\right.$ & $0,102\left(^{2}\right)$ \\
\hline Diluvium + Cailloux : DC & $0,942 \mathrm{C}$ & $2,519 \mathrm{~A}$ & $0,108 \mathrm{~A}$ \\
\hline Dil. Régul' Irrigué : DRI & $0,864 \mathrm{~B}$ & $3,978 \mathrm{C}$ & $0,108 \mathrm{~A}$ \\
\hline Diluvium Amendé : DA & $0,943 \mathrm{C}$ & $2,574 \mathrm{~A}$ & $0,106 \mathrm{~A}$ \\
\hline Limon Argilo-Calcaire: LAC & $0,827 \mathrm{~A}$ & $2,968 \mathrm{~B}$ & $0,123 \mathrm{~B}$ \\
\hline
\end{tabular}

(1) Seules, les moyennes suivies de lettres différentes peuvent être considérées comme significativement différentes, selon le test de NewmanKeuls, au seuil de $5 \%$.

(2) Moyenne non comparée statistiquement (a priori distincte des autres mais effectif différent).

puisque les prélèvements avaient été regroupés par paire d'arbres (cf. paragraphe II E). Cependant, compte tenu de la nature du traitement qui est assez drastique par rapport aux autres, les résultats correspondants se démarquent toujours assez nettement de ceux des autres traitements. Aussi, pour éviter des difficultés liées aux différences d'effectifs, n'avons-nous comparé statistiquement que les moyennes des 5 autres traitements, en considérant $a$ priori la moyenne DVR comme distincte. Cependant, pour chaque cation, nous avons tenu compte de l'ordre de grandeur de la ppds pour vérifier que l'écart de la moyenne DVR avec les autres offrait une sécurité suffisante.

Les résultats concernant l'ion potassium montrent des écarts significatifs. La comparaison des moyennes des teneurs de cet ion à l'aide du test de NewmanKEULS permet de les classer de la façon suivante (par ordre croissant au seuil de 5 p. 100).

$$
\text { LAC - DRI - (DC, DA, DT) puis DVR. }
$$

Indépendamment des arbres cultivés sur limon, pour lesquels la balance ionique est particulière, le classement obtenu est assez semblable à celui concernant les contraintes hydriques. Cela est probablement à mettre en relation avec le rôle régulateur et compenseur de ce cation dans le métabolisme de l'eau (HuDSON, 1958, BLANCHET et al., 1962). En particulier, les arbres cultivés en petit bac et soumis à des contraintes hydriques élevées auraient eu tendance à accumuler plus de potassium pour compenser les difficultés d'absorption d'eau (SALSAC, 1977 et communication personnelle).

Les écarts entre les teneurs en calcium sont encore plus importants. Le test de NEWMAN-KeUlS permet leur classement statistique au seuil de 5 p. 100 de la façon suivante (par ordre croissant) :

$$
\text { DVR puis (DC, DA, DT) - LAC - DRI -. }
$$

Dans ce cas, un parallèle étroit apparaît avec le classement des quantités d'eau consommées (tabl. 2), ce qui $a$ priori peut être attribué à l'influence des flux d'eau sur les possibilités de transit de cet ion peu mobile dans la plante (GRIGNON, communication personnelle) ; mais nous reviendrons plus en détail sur ce point dans la discussion.

En ce qui concerne le magnésium, les teneurs obtenues sont plus groupées. On peut malgré tout statisti- quement faire les distinctions suivantes (par ordre croissant et au seuil de 5 p. 100).

DVR puis (DA, DC, DT, DRI) - LAC - .

Ici, plusieurs facteurs (eau consommée, quantités de magnésium disponibles dans le substrat, balance entre les divers cations...) interviennent probablement de manière simultanée. La forte teneur des arbres cultivés sur limon est probablement à associer à la bonne richesse en $\mathrm{Mg}$ de ce substrat, combinée à un fonctionnement hydrique assez satisfaisant.

\section{Sensibilité comparée des pêchers}

Selon les traitements, les longueurs atteintes par les lésions provoquées par inoculation se sont révélées assez différentes. Le phénomène est illustré par le graphique de la figure 3 où sont portées entre autre les moyennes de ces longueurs en $\mathrm{mm}$.

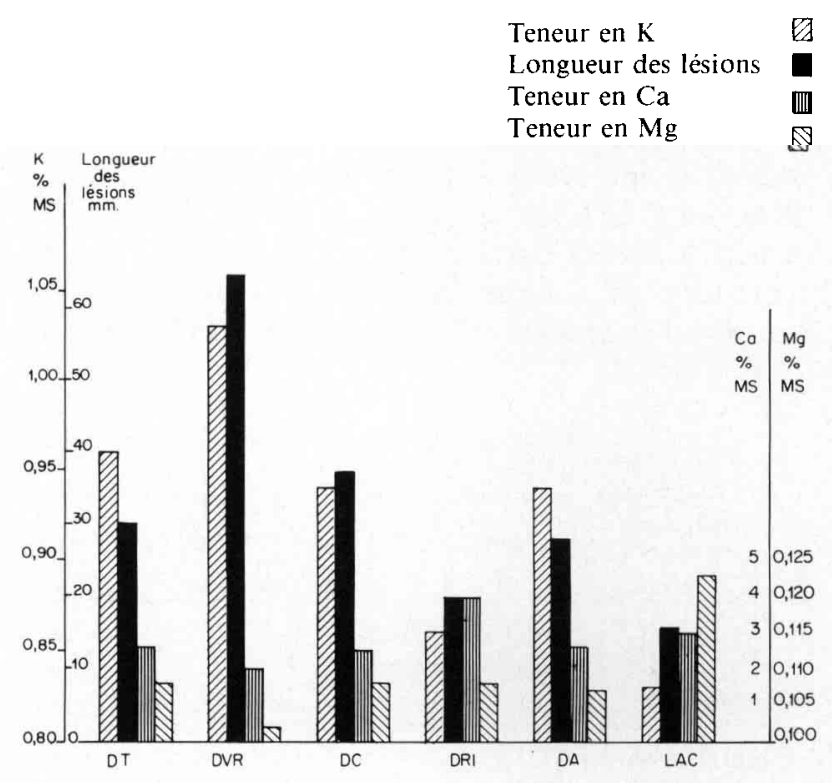

Figure 3

Parallele, par arbre et par traitement, entre la longueur moyenne des lésions bactériennes provoquées par inoculation sur les rameaux des pêchers et les teneurs en cations principaux.

Parallel, per tree and per treatment, between mean length of bacterial lesions artificially induced on peach twigs and contents of the principal cations. 
Cependant, compte tenu du caractère exponentiel de l'allongement des lésions et pour pouvoir valablement comparer les écarts entre les divers traitements, il est nécessaire de traduire l'importance de ces lésions en transformant leur longueur selon un système de classes de 0 à 10 alignées sur une progression logarithmique spécialement adaptée (LUISETTI, 1983).

Le détail des notations par arbre selon cette échelle (tabl. 4) et leur analyse statistique permettent de classer et de distinguer les effets des traitements de la façon suivante : (au seuil 5 p. 100 et par ordre d'importance des lésions croissantes).

$$
\text { (LAC, DRI) - (DA, DT) - DC - DVR. }
$$

Il apparaît ainsi qu'une diminution du volume du sol (DVR) à la disposition du système radiculaire des arbres ou une augmentation de la charge en cailloux du substrat (DC) ont entraîné une sensibilisation des pêchers. L'accroissement est net pour l'apport de cailloux et très important pour la réduction du volume de substrat.

A l'inverse, l'irrigation régulière (traitement DRI) a entraîné une forte réduction de la sensibilité, au point de rendre cette dernière proche (non significativement différente) de la tolérance des arbres cultivés sur limon calcaire en irrigation périodique.

L'amendement du diluvium par la chaux n'a pas provoqué d'amélioration de la résistance des pêchers, au moins appréciable statistiquement et dans ces conditions de travail.

\section{Corrélations entre la sensibilité des arbres et leur composition minérale}

Puisque des différences significatives ont pu être établies entre les teneurs des arbres en cations selon les traitements, on doit chercher si parallèlement à des différences de sensibilité, des corrélations existent entre ces divers phénomènes.

Le simple rapprochement des valeurs obtenues par traitement (fig. 3 et tabl. 3) suggère déjà nettement des corrélations assez fortes entre teneurs des 3 cations et importance des infections.

Pour une analyse statistique plus précise et plus exhaustive de ces corrélations, il semble plus adapté de prendre en compte les valeurs individuelles par arbre. Pour le traitement petit volume (DVR) nous ne disposons que de teneurs minérales moyennes par paire d'arbre ; nous les rapprocherons de la moyenne des notations d'infections obtenues sur les 2 arbres correspondants. Par ailleurs, un arbre du traitement limon calcaire ne s'est pas développé. On dispose donc en tout d'un effectif de 54 individus à analyser et le calcul à partir de ces divers éléments permet de dresser la matrice de corrélation suivante (au seuil 1 p. 100).

\begin{tabular}{ccccc}
\hline \hline & Lésions & $\mathrm{K}$ & $\mathrm{Ca}$ & $\mathrm{Mg}$ \\
\hline Lésions & 1000 & $+0,717$ & $-0,591$ & $-0,409$ \\
\hline $\mathrm{K}$ & & 1,000 & $-0,614$ & $-0,380$ \\
\hline $\mathrm{Ca}$ & & & 1,000 & $+0,240$ \\
\hline $\mathrm{Mg}$ & & & & 1,000 \\
\hline
\end{tabular}

Selon les cations, les corrélations apparaissent donc comme fortes $(\mathrm{K})$, assez fortes $(\mathrm{Ca})$ à notables $(\mathrm{Mg})$.

\section{DISCUSSION}

\section{A. Aspects généraux ; conditions d'expérimentation}

Il est nécessaire avant tout d'analyser la validité d'études en conteneur prétendant s'intéresser à des phénomènes liés au fonctionnement du système solplante.

Nous devons souligner à ce propos qu'au champ le Dépérissement bactérien affecte souvent les pêchers dès leur première année de végétation. Ces végétaux se développent alors dans un sol encore peu organisé après la réalisation du labour de défoncement et l'agencement des diverses particules de terre, les conditions de circulation de l'eau ou de l'air par exemple, se rapprochent beaucoup de ceux du substrat de nos bacs. Par ailleurs, dans cet essai, le volume de substrat, utilisé pour une année de végétation seulement, permettait un développement très libre du système radiculaire, comme l'ont montré des examens à ce

TABLEAU 4

Importance moyenne, au niveau de chaque pêcher traité, des lésions bactériennes induites par inoculation sur rameau. Mean level, for each treated peach tree, of bacterial cankers artificially induced on twigs.

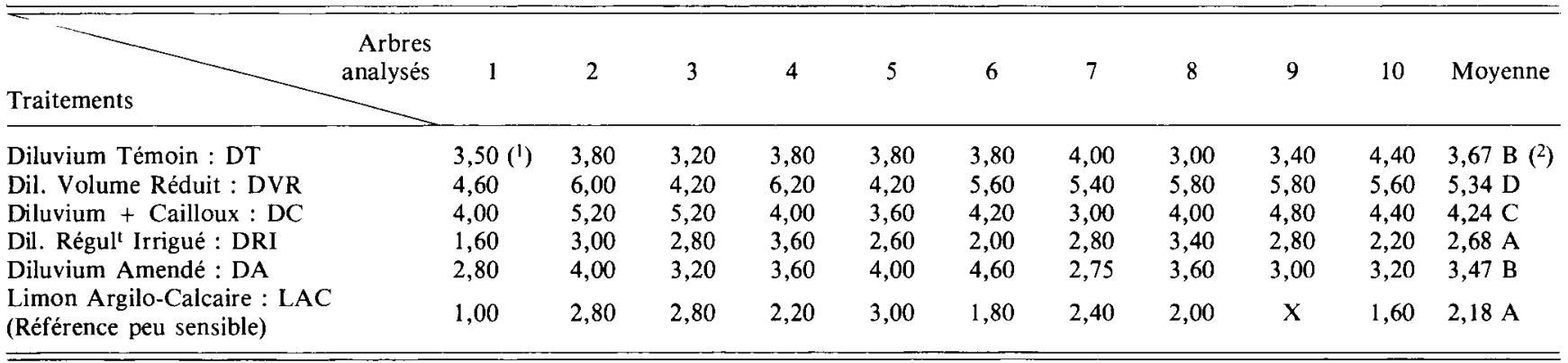

(1) Moyenne des résultats de cinq inoculations par arbre (en échelle logarithmique).

(2) Seules, les moyennes suivies de lettres différentes peuvent être considérées comme différentes selon le test de Newman-Keuls, au seuil de $5 \%$. 
niveau en fin de culture. Cependant, nous nous sommes affranchis de l'influence des couches de sol profondes qui peuvent dans certaines situations avoir une incidence très importante (KATERJI et al., 1984). En fait, pour les sols qui nous occupent, nous pensons que cette influence est assez limitée. Les profils culturaux permettent de constater combien les racines du pêcher sont localisées à l'horizon supérieur limonosableux $(50 \mathrm{~cm})$, colonisant même difficilement les parties d'horizon B plus argileux remontées (et donc ameublies) dans la partie de sol défoncée. Par ailleurs, les couches profondes sont constituées par les terrasses caillouteuses anciennes du Rhône (BORNAND, 1968) contenant très peu d'eau.

Enfin, il est essentiel de souligner que l'influence des facteurs analysés n'est appréciée qu'à travers l'effet de leurs variations et non en fonction de leur présence ou de leur absence. Ce raisonnement "en relatif » avec référence non seulement à 1 mais à 2 types de témoins nous semble limiter fortement les inconvénients de la formule d'étude et permettre d'extrapoler de façon plus réaliste aux conditions du plein champ.

On peut par contre penser que par rapport à des modèles d'étude plus simples et très contrôlés du type culture hydroponique, les facteurs étudiés gardent leur importance relative réelle et que, plus largement, l'étude de l'incidence effective des facteurs du système cultural exige d'être faite sur une plante végétant dans des conditions très proches de celles du système concerné. L'étude précise des mécanismes des facteurs dégagés peut ensuite être abordée en conditions contrôlées et le sera alors sur des bases mieux définies.

Sur le plan purement pathologique, les différences de sensibilité induites par les traitements sont importantes bien que, en absolu, les longueurs de lésion obtenues soient généralement assez limitées. Ce dernier point est à mettre en relation avec la date tardive d'inoculation. De toutes façons, on peut relativiser les écarts obtenus en se référant à celui observé entre diluvium témoin et limon calcaire, tous 2 arrosés périodiquement : cet écart correspond à un accroissement de 100 p. 100 pour des lésions mesurées en millimètres, ou de 68,3 p. 100 en notation à échelle logarithmique ; ce qui est déjà conséquent.

\section{B. Incidence des facteurs culturaux étudiés}

\section{Volume de sol réduit}

L'accroissement de la sensibilité des arbres cultivés en volume réduit est très marqué. On a vu que ces arbres ont subi des contraintes hydriques particulièrement élevées (mais pas irréalistes par rapport à ce que l'on observait dans des vergers proches) et la consommation totale d'eau était bien inférieure à celle des arbres témoins (de 35 p. 100 en moyenne).

Il est possible que ces différences ne soient pas les seuls facteurs en jeu dans nos conditions d'expérimentation car la comparaison entre volumes différents fait intervenir en même temps des phénomènes annexes, tels l'inertie thermique de la masse de substrat ou des effets de paroi relativement plus importants, ce qui peut biaiser légèrement l'expérimentation. Il semble malgré tout que la notion de volume réduit soit la plus importante et, en conséquence, on peut supposer qu'au champ la faible profondeur $(25$ à $50 \mathrm{~cm})$ ou le volume réduit de sol exploités dans les sols prédisposants constituent en eux-mêmes des éléments notables de prédisposition. Une possibilité d'améliorer la résistance des pêchers sur de tels sols serait donc d'augmenter les capacités d'enracinement et de colonisation du sol. Des essais visant à réaliser une préparation du sol adaptée sous forme d'ameublissement en profondeur sans retournement des divers horizons, sont prévus.

\section{Forte proportion de cailloux dans le sol}

L'accroissement de la charge en cailloux (DC) a aussi entraîné une augmentation de la sensibilité des pêchers mais à un degré moindre ; de l'ordre du tiers de l'écart entre les 2 témoins. Par rapport à la référence diluvium, les quantités d'eau consommées mesurées sont en moyenne du même ordre. Or, la réserve en eau du substrat a dû être réellement abaissée ; la nature des cailloux choisis, alliée à une fraction de terre fine surtout sableuse n'offrait que très peu de possibilités de stockage d'eau (GRAS \& MONNIER, 1962). Il faudrait alors envisager que l'eau retenue par le substrat ait été utilisée plus à fond, peut être grâce à une énergie d'absorption par les racines augmentée à la suite d'une meilleure aération du substrat (CHANG \& LOOMIS, 1945 ; KRAMER, 1945 ; HOPKINS et al., 1950). En effet, bien que ce type de terre soit considéré a priori comme aéré, il n'est pas impossible que l'oxygène s'y situe à un niveau encore limitant, amélioré par l'accroissement de la teneur en cailloux.

On peut penser cependant que ces arbres ont plus souffert que les arbres témoins car, au moins dans la deuxième séquence de dessèchement, les courbes d'évolution du potentiel de base sont nettement distinctes (fig. 2) et, durant le jour, des écarts ont dû se constituer très souvent, pour tous les cycles lors des périodes de forte évapo-transpiration. D'autre part, ces arbres ont perdu leurs feuilles légèrement plus tôt que les arbres témoins. On peut supposer que l'on retrouve ici le manque relatif de sensibilité déjà signalé (GARNIER, 1985) du potentiel de base mesuré au niveau des feuilles pour refléter les difficultés du végétal à extraire l'eau du sol. La régulation stomatique des consommations d'eau (KLEEPER, 1968), évidemment plus forte en cas de moindre disponibilité de l'eau, explique probablement aussi partiellement cette absence de différence avec le témoin.

Quoi qu'il en soit, il apparaît aussi expérimentalement qu'au moins en sol acide, une trop forte proportion de cailloux comme un volume du sol disponible limité constituent des éléments de prédisposition des pêchers au Dépérissement bactérien et qu'il doit en être tenu compte dans le choix des parcelles à planter.

\section{Amendement chaulé}

L'absence d'effet significatif de l'amendement chaulé (tabl. 4) peut surprendre puisqu'une des caractéristiques essentielles des terres prédisposantes est leur acidité. En fait, on doit se rappeler les résultats irréguliers des essais antérieurs. Certains avaient permis de mettre en évidence un léger effet bénéfique de ce type d'amendement. Mais il s'agissait d'expérimen- 
tations réalisées en conteneurs de $100 \mathrm{l}$, très voisins de ceux utilisés ici pour le traitement DVR ; ce qui semble constituer des conditions plus sévères et peut être plus aptes à révéler un effet limité de l'amendement.

D'ailleurs, les effets d'un amendement sont multiples et souvent peu rapides même en utilisant une chaux très fine. En outre, nous devons signaler que, dans le cadre d'une expérimentation parallèle portant sur les mêmes arbres que ceux de l'étude traitée ici, nous avons pu constater, pour ce même traitement une amélioration de résistance sur certaines parties d'organes seulement (VIGOUROUX et al., en préparation).

On peut, enfin, se poser la question de la valorisation d'un amendement calcique, ou même plus généralement basique, dans un sol insuffisamment humecté. Les échanges se faisant dans la solution du sol (FREID \& SHAPIRO, 1961 ; ANSTETT, 1964) une irrigation plus régulière (du type du traitement DRI) aurait peut-être amélioré l'efficacité de l'apport de chaux. Un essai cherche actuellement à vérifier ce point.

\section{Irrigation régulière}

La réduction de sensibilité des arbres arrosés plus régulièrement et plus copieusement est très importante puisque les lésions obtenues sont presque aussi limitées que celles produites sur les arbres cultivés sur limon (fig. 3, tabl. 4).

On peut penser que ce résultat est à associer à l'absence de contrainte hydrique subie par les arbres (fig. 2) et à l'accroissement des quantités d'eau consommées (fig. 1 et tabl. 2). En réalité ces 2 éléments n'impliquent pas exactement les mêmes phénomènes au niveau de la physiologie de l'arbre, comme nous le verrons un peu plus loin.

On peut au moins affirmer que la régularisation de l'irrigation réalisée avec l'eau dont nous disposions dans cette région a entraîné une nette amélioration de la résistance des arbres. Ainsi, globalement, est mis en évidence sur le plan pratique une base d'intervention de type prophylactique et même à inclure dans le cadre d'une «protection intégrée » au sens large.

Il faut d'ailleurs souligner que ce type de solution ne conduirait pas à doubler les doses d'eau à l'hectare utilisées actuellement. Chaque apport est généralement bien supérieur à la capacité de rétention en eau des sols et une partie en est gaspillée. Par ailleurs, la dépense d'une même quantité d'eau par hectare utilisée par aspersion en pleine surface ou répartie de façon localisée au pied de chaque arbre correspond dans le second cas, à une dose efficace par arbre nettement plus élevée. Ainsi, avec les mêmes dépenses d'eau annuelles, le résultat recherché pourrait être acquis et il nous apparaît alors que l'extension de la pratique de l'irrigation localisée peut constituer un moyen très intéressant pour limiter l'incidence du Dépérissement bactérien.

\section{Essai d'interprétation de ces résultats}

Les analyses minérales des écorces de rameaux, prévues pour apporter quelques éléments d'explications aux phénomènes observés, ont fourni des résultats assez tranchés ( $\S \mathrm{B}$ et $\mathrm{D}$ des résultats).

\section{Incidence du Calcium}

A priori, les réponses obtenues à propos du calcium (corrélation positive assez forte avec la résistance) pouvaient être au moins en partie attendues, étant données les grandes différences de comportement des vergers en zones acides et calcaires. Pourtant, aucun des essais antérieurs, réalisés en conteneurs de faible volume ou en pleine terre, n'avait permis de mettre en évidence une variation de teneur en calcium même en cas d'amélioration de la résistance. L'importance de l'éventail des teneurs obtenues ici explique peut-être ce résultat positif.

Par ailleurs, on sait déjà que le calcium a été souvent cité, en pathologie végétale, pour intervenir clairement dans les relations hôte-parasite. Il s'agit le plus souvent de maladies dues à des champignons (CORDEN, 1965; DOUPNIK, 1968 ; MUCHOVEJ et al., 1980 ; PERRIN \& GARBAYE, 1984 ; PONCHET et al., 1984), etc...) mais la bibliographie rapporte aussi un rapprochement analogue à celui constaté ici pour quelques maladies bactériennes (THOMAS et al., 1948 ; Mc GUIRE \& KELMAN, 1984).

Dans le cas de l'infection du Pêcher par Ps. persicae, plusieurs modes d'action sont envisageables pour le calcium. On doit d'abord penser à son rôle de consolidation des parois cellulaires (GINZBURG, 1961; MARINOS, 1962 ; SIMON, 1978 ; CLARKSON \& HANSON, $1980 ; \ldots$ ) qui peut jouer à deux niveaux : réduire les microlésions liées au gel qui permettent la pénétration de la bactérie dans l'hôte (DURAND et al., 1967 ; LUISETTI, 1983), freiner la désorganisation des parois liée à l'activité bactérienne (DAVIS \& ENGLISH, 1969 ; Mc GuIRE \& KELMAN, 1986). A un niveau proche, $P$ s. persicae produit une toxine (LUISETTI, 1983) homologue, semble-t-il, de la syringomycine produite par une bactérie apparentée, Ps. syringae, (SINDEN et $a l ., 1971)$. Or, il a été montré que cette syringomycine agit sur l'intégrité de la membrane cellulaire et que les ions $\mathrm{Ca}^{++}$ont un important pouvoir d'inhibition de cette toxine (BACKMAN \& DEVAY, 1971).

D'autre part, il a été établi que les températures négatives favorisaient le développement de l'infection par $P_{S}$. persicae et la principale explication avancée pour au moins une partie de cette action favorisante (VigourouX, 1979) était que le phénomène de congestion (rameaux d'aspect vitreux) lié à l'adaptation au froid, par migration de l'eau cellulaire dans les méats intercellulaires (WIEGAND, 1906; MODLIBOWSKA, 1961 ; LEVITT, 1972), créait un continuum liquide, surtout au moment du dégel, qui favorise beaucoup la diffusion de tout micro-organisme et de ses éventuelles toxines (JOHNSON, 1945). Cela a d'ailleurs été montré précisément pour des bactéries pathogènes (BRAUN \& JOHNSON, 1939 ; DIACKUN et al., 1944 ; DAINES, 1961 ; WILliams \& KEEN, 1967). Or, le calcium qui est connu pour réduire la perméabilité des membranes cellulaires (POOVAIAH \& LEOPOLD, 1976 ; CLARKSON \& HANSON, 1980) peut limiter l'importance de cette congestion des tissus et réduire ainsi les possibilités de diffusion de la bactérie par cette voie. 
Enfin, il a été constaté in vitro une action directe du calcium sur les aptitudes pathogènes de Ps. persicae par diminution de la proportion de cellules toxigènes au sein d'une souche bactérienne donnée (LUISETTI, 1983 ) et il est logique d'envisager la réalisation de phénomènes analogues in vivo même si le taux de calcium libre dans le cytoplasme ou ailleurs est très faible.

Les arguments sont donc nombreux pour penser que la corrélation positive entre teneur en calcium et tolérance à l'infection des pêchers reflète une relation de nature causale.

Cependant, l'importance de ces teneurs de calcium et leurs conséquences nous amène à préciser leur origine.

La meilleure humectation du substrat provoquée par notre irrigation régulière permet une meilleure mobilisation du calcium du sol et sa meilleure absorption, en relation avec des flux d'eau plus élevés au niveau des racines (MAERTENS \& ClAuZEL, 1980). De même, le transit de cet ion peu mobile dans la plante vers les extrémités a-t-il pu être activé par l'accroissement des flux d'eau associé à l'accroissement de l'évapo-transpiration (EPSTEIN, 1972; STEBBINS \& DEWEY, 1972 ; WIEBE et al., 1977 ; BANGERTH, 1973, 1979). Mais, en parallèle, le degré hydrotimétrique élevé de l'eau utilisée pour l'irrigation implique que la solution du sol ait été enrichie directement de façon exogène en ions $\mathrm{Ca}^{++}$facilement assimilables.

Aussi, peut-on penser que l'importance de l'augmentation de la teneur en calcium des rameaux et la diminution de sensibilité qui lui semble associée soient dues à la fois à une meilleure disponibilité de l'eau dans le substrat (et à sa plus grande consommation) et au caractère calcaire de l'eau d'irrigation agissant comme un correctif.

Sur le plan pratique, cette constatation n'enlève rien au poids de l'incidence de l'irrigation échelonnée sur la résistance des arbres car, dans les régions concernées par le Dépérissement bactérien, comme d'ailleurs dans pratiquement toutes les zones de culture du Pêcher en France, l'eau d'irrigation est calcaire et peut jouer le rôle de correctif évoqué plus haut.

Un début de confirmation de cette possibilité a d'ailleurs pu être observé par hasard : pour un type de sol identique, puisqu'il s'agit de celui même du domaine de Gotheron situé sur terrasse ancienne, un essai sur pêcher en verger en pleine terre, mettant en jeu deux doses et deux répartitions d'irrigation, a permis d'augmenter nettement les teneurs en calcium des arbres arrosés plus abondamment et de façon échelonnée (ARNOUX, publication en préparation).

Par contre, sur le plan de la physiologie de l'arbre, il n'est pas possible de savoir dans quelle mesure l'arbre est plus résistant parce que sa contrainte hydrique a été réduite ou parce qu'il a bénéficié d'un apport généreux de calcium en partie indépendant du sol. L'expérimentation que nous menons actuellement en comparant irrigation épisodique ou régulière, avec eau calcaire et eau pure, dans le même type de dispositif, devrait apporter des précisions dans ce sens. La combinaison avec un amendement chaulé en réhausse l'intérêt.

\section{Incidence du Potassium}

La corrélation entre teneur en potassium et sensibilité des arbres est élevée $(r=+0,717)$ mais nous disposons de peu d'éléments pour soutenir l'éventualité d'une relation de cause à effet. De même que nous pouvions avancer que les terres prédisposantes manquaient de calcium, de même on peut dire qu'elles sont le plus souvent largement pourvues en potassium, ce qui permettrait une relation avec le développement de la maladie. De plus, il existe un certain antagonisme entre absorption de $\mathrm{K}$ et $\mathrm{Ca}$, qui doit jouer au détriment du calcium beaucoup moins abondant (cf. analyse tabl. 1).

En parallèle, il a déjà été signalé une relation entre fertilisation potassique, augmentation de la teneur de pêchers adultes en $\mathrm{K}$ et augmentation de leur sensibilité à la maladie des taches bactériennes sur feuille (ThOMAS et al., 1948).

La teneur en $\mathrm{K}$ étant spécialement élevée chez les plantes ayant souffert de contrainte hydrique excessive, il semble qu'il nous faille d'abord établir les conséquences de ce "stress" étudié en lui-même pour approcher plus facilement le rôle du potassium. Mais n'oublions pas non plus son importance sur le métabolisme de l'eau en général y compris en hiver. Il pourrait donc influencer le comportement des plantes au froid, ce dernier facteur constituant lui-même, comme on l'a vu, un élément essentiel de prédisposition du Pêcher au Dépérissement bactérien.

\section{Incidence du Magnésium}

La corrélation entre teneur en $\mathrm{Mg}$ et sensibilité des arbres est simplement moyenne $(r=-0,409)$. Les relations de ce cation avec les précédents et, en quelque sorte, sa position intermédiaire entre eux sur le plan des propriétés biochimiques et biophysiques rendent toute interprétation délicate.

On peut simplement relever qu'il est souvent déficient dans les terres prédisposantes mais aucune expérimentation s'appuyant sur cet élément seul n'a donné un résultat appréciable. Ce n'est évidemment pas un argument suffisant pour exclure un rôle de sa part compte tenu de la finesse des équilibres en jeu. Il faut enfin, signaler la forte teneur en $\mathrm{Mg}$ des arbres résistants développés sur limon calcaire, qui semble compenser leur teneur assez modeste en calcium.

\section{Conclusion générale}

En plus de leur acidité, quelques caractéristiques des sols des régions affectées par le Dépérissement bactérien paraissent bien impliquées dans la prédisposition des pêchers; en particulier leur caractère peu profond, difficile à exploiter par les racines et leur caractère fortement caillouteux ou graveleux. Aggravant ces données, le manque d'échelonnement dans l'irrigation intervient ensuite de façon nette pour fournir aux arbres une alimentation hydrique et une nutrition qui se révèlent très déficientes. En particulier, de faibles niveaux de cations comme le magnésium et surtout le calcium, mais peut-être aussi de fortes teneurs en potassium semblent associés à la prédispo- 
sition des arbres. Plusieurs expérimentations tentent actuellement d'obtenir des précisions dans ce sens.

Si le mode d'action de ces cations était confirmé, le mode de prédisposition marqué des arbres par le froid, dans lequel ces éléments jouent très probablement un rôle important, pourrait constituer une voie d'étude intéressante.

Il reste enfin à déterminer d'autres facteurs de résistance possibles, ceux permettant par exemple aux arbres cultivés sur limon d'être résistants même en conditions de contrainte hydrique assez poussée, avec des teneurs en calcium des tissus très modestes.

Reçu le 20 juin 1986 Accepté le 20 mars 1987
REMERCIEMENTS

Nous tenons à remercier ici les collègues de différentes disciplines, cités en cours de texte, qui, par leurs conseils, leur avis ou même certaines mesures, m'ont permis de mieux analyser ou interpréter les nombreux aspects de ce travail qui empiète largement sur des domaines plus ou moins éloignés (a priori) de la phytopathologie. Ce sont, à titre de rappel, MM. M. Bornanis el G. CAI.tot du laboratoire de recherche de la chaire de Science du sol, INRA-ENSA Montpellier ; LuC J. P., de l'unité de recherche et d'enseignement de génie rural et machinisme agricole ENSA-Montpellier ; MAERTENS C. de la Station d'Agronomie INRA-Toulouse; SAl.SAC L. de l'unité de recherche et d'enseignement de Biochimie, physiologie et nutrition des végétaux, ENSA-INRA Montpellier; SCHOCH P. G. de la station de Bioclimatologie, INRA Avignon-Montfavet.

J'ajouterai aussi tous mes remerciements aux lecteurs, et spécialement à M. SEBILLOTTE, pour toutes les corrections apportées et suggestions émises pour améliorer ce travail.

\section{RÉFÉRENCES BIBLIOGRAPHIQUES}

Anstett A., 1964. Conséquences de l'irrigation du point de vue des fumures en culture maraîchère. Agriculture, 1, 19-22.

Appel O. N., Stipes R. J., 1984. Canker expansion on waterstressed pin oak colonised by Endothia gyrosa. Plant Dis., 68, 851853.

Aussenac, Granier L., 1978. Quelques résultats de cinétique journalière du potentiel de sève chez les arbres forestiers. Ann. Sci. for., 35 (1), 19-32

Backman P. A., Devay J. E., 1971. Studies on the mode of action and biogenesis of the phytotoxin syringomycin. Physiol. Plant Pathol., 1, 215-233.

Bangerth B., 1973. Investigation upon Ca related physiological disorders. Phytopathol. Z., 77, 20-37.

Bangerth B., 1979. Calcium-related physiological disorders of plants. Ann. Rev. Phytopathol., 17, 97-112.

Bertrand P. F., English H. Uriu K., Schick F. J., 1976. Late season water deficit and development of cytospora canker in French prune. Phytopathology, 66, 1318-1320.

Bier J. E., 1964. The relation of some bark factors to canker susceptibility. Symposium on cankers of forest trees. Phytopathology, 54, 250-253.

Blanchet R., Studer R., Chaumont C., 1962. Quelques aspects des interactions entre l'alimentation potassique et l'alimentation hydrique des plantes. Ann. Agron., 13 (2), 93-110.

Bloomberg W. J., 1962. Cytospora canker of poplars: factors influencing the development of the disease. Can. J. Botan., 40, 10 : 1271-1280.

Bornand M., 1968. Etude pédologique dans la vallée du Rhône. Plaine de Valence. Romans. Rapport du Service d'Etude des Sols. I.N.R.A. Montpellier.

Boyer J. S., 1967. Leaf water potentials measured with a pressure chamber. Plant Physiol., 42, 133-137.

Braun A. C., Johnson J., 1939. Natural water-soaking and bacterial infection. Phytopathology, 29.1 (abst.).

Chang H. T., Loomis W. E., 1945. Effect of carbon dioxide on absorption of water and nutrients by roots. Plant Physiol., 20, 221232.

Clarkson D. T., Hanson J. B., 1980. The mineral nutrition of higher plants. Ann. Rev. Plant Physiol., SL31, 239-298.

Corden M. E., 1965. Influence of calcium nutrition on Fusarium wilt of tomato and polygalacturonase activity. Phytopathology, 55, 222-224.

Cummings G. A., 1973. The distribution of elements in "Elberta " peach tree tissues and the influence of potassium and magnesium fertilization. J. Am. Soc. hort. Sci., 98 (5), 474-477.

Diackun S., Valleau W. D., Johnson E. M., 1944. Invasion of water-soaked tobacco leaves by bacteria, solutions and tobacco mosaic virus. Phytopathology, 34, 250-253.
Daines R. H., 1961. What we know about bacterial spot of peach. Hortic. News (New Jersey) 42, 110.

Davis S. R., English H., 1969. Factors related to the development of bacterial canker in peach. Phytopathology, 59, 588-595.

Doupnik B., 1968. The suppression of victorin-induced disease by calcium. Phytopathology, 58, 215-218.

Durand R., Luisetti J., Meynier M.,' Ride M., 1967. Infektion durch Pseudomonas syringae nach leichten Frost. X. Agrarmeteorogisches Dreilandertreffen Bavendorf, 3 p.

Epstein E., 1972. Mineral nutrition of plants : principles and perspectives. (John Wiley and Sons, New York, ed.) $412 \mathrm{p}$.

Ferrario S., Poupet A., Blanc D., 1985. Influence de la nutrition calcique sur la multiplication du virus de la mosaique du tabac chez le tabac (Nicotiania tabacum L. var. "Xanthi n. c." et "Samsun ") Agronomie, 5 (6) 521-528.

Fried M., Shapiro R. E., 1961. Soil plant relationships in ion uptakes. Ann. Rev. Plant Physiol., 12, 91-112.

Garnier E., 1985. Dessèchement du sol et indicateurs physiologiques de l'état hydrique chez le Pêcher; application au déclenchement de l'irrigation. Thèse docteur-ingénieur, ENSA Montpellier, $82 \mathrm{p}$.

Ginzburg B. Z., 1961. Evidence for a protein gel structure crosslinked by metal cations in the intercellular cement of plant tissue. $J$. exp. Bot., 12, 85-107.

Gras R., 1962. Quelques observations sur les relations entre les propriétés physiques du sol et la croissance du Pêcher dans la Vallée du Rhône, entre Vienne et Valence. Ann. Agron., 13 (2), 141-174.

Gras R., Monnier G., 1962. Contribution des cailloux à la capacité de réserve en eau du sol. C.R. Acad. Sci. D., 254, 3422-3424.

Henin S., Gras R., Monnier G., 1969. Le profil cultural, réed., 230 p., S.E.I.A. Paris.

Hopkins H. T., Specht A. W., Hendricks S. B., 1950. Growth and nutrient accumulation as controlled by oxygen supply to plant roots. Plant Physiol., 25 (2), 193-209.

Hudson J. P., 1958. General effect of potassium on the water economy of plants. In Potassium Symposium, 95-108. Instit. Intern. Potasse, Berne.

Huguet C., 1981. Nutrition des arbres fruitiers. Evolution des concepts. Agriculture, 448, 13-16.

Huguet C., 1982. Relation entre la nutrition de l'arbre et les maladies physiologiques ou de conservation des fruits. C.R. $2^{e}$ Coll. Rech. fruitieres. Bordeaux, 17-18 mars 1982, 137-149.

Johnson J., 1945. Infection experiments with detached watercongested leaves. Phytopathology, 35, 1017-1028.

Katerji N., Daudet F., Valancogne C., 1984. Contribution des réserves profondes du sol au bilan hydrique des cultures. Détermination et importance. Agronomie, 4 (8), 779-787.

Kleeper B., 1968. Diurnal pattern of water potential in woody plants. Plant Physiol., 43, 1931-1934. 
Kramer P. J., 1945. Absorption of water by plants. Bot. Rev., 11, 310-355.

Levitt J., 1972. Responses of plants to environmental stress. New York, Academic Press, 697 p.

Lewis T. L., Martin D., Cerny J., Ratkowsky D. A., 1977. The effects of increasing the supply of nitrogen, phosphorus, calcium and potassium to the roots of Merton Worcester apple trees on leaf and fruit composition on the incidence of bitter pit at harvest. $J$. hort. Sci., 52, 409-419.

Luisetti J., 1983. Quelques aspects de la variabilité de Pseudomonas persicae, agent du dépérissement bactérien du Pêcher. C.R. $3^{e}$ Coll. Rech. fruitières, Bordeaux, 28-29 nov., 187-200.

Mc Guire R. G., Kelman A., 1984. Reduced severity of Erwinia soft rot in potato tubers with increased calcium content. Phytopatho$\log y, 74,1250-1256$.

Mc Guire R. G., Kelman A., 1986. Calcium in potato tuber cell walls in relation to tissue maceration by Erwinia carotovora pv. atroseptica. Phytopathology, 76, 401-406.

Maertens C., 1964. Influence des propriétés physiques des sols sur le développement radiculaire et conséquences sur l'alimentation hydrique et azotée des cultures. Sci. Sol, 2, 31-39.

Maertens C., Cabelguenne M., 1974. Intensité et limite du dessèchement du sol en relation avec l'enracinement de quelques espèces végétales. C.R. Acad. Sci. Paris sér. D., 279, 2039-2043.

Maertens C., Clauzel Y., 1980. Rôle du flux de sève dans les racines sur l'absorption de l'azote nitrique, du potassium et du calcium par les systèmes racinaires de jeunes plantes de Zea mais. C.R. Acad. Sci. Paris, 290, série D, 1285-1287.

Manichon H., 1982. Influence des systèmes de culture sur le profil cultural: élaboration d'une méthode de diagnostic basée sur l'observation morphologique. Thèse ingénieur docteur INA ParisGrignon, $214 \mathrm{p}$.

Matthee F. N., Daines R. H., 1968. Effects of soil types and substrate aeration on stomatal activity, water diffusion, pressure deficit, water congestion and bacterial infection of peach and pepper foliage. Phytopathology, 58, 1298-1301, 1298-1301.

Marinos N. G., 1962. Studies on submicroscopic aspects of mineral deficiencies. I. Calcium deficiency in the shoot apex of barley. Ann. J. Bot., 49, 834-841.

Modlibowska Irène, 1961. Sur les mécanismes du gel et de la reprise d'une vie normale au retour de la température ordinaire. Bull. Soc. fr. Physiol. Veg., 7 (4), 122-133.

Moore L. W., Lagerstedt H. B., Hartman N. W., 1974. Stress predisposing young filbert trees to bacterial blight. Phytopathology, 64, 1537-1540.

Muchovej J. J., Muchovej R. M. C., Dhingra O. D., Maffia L. A., 1980. Suppression of anthracnose of soybeans by calcium. Plant Dis., 64, 1088-1089.

Perrin R., Garbaye J., 1984. Influence de la nutrition du Hêtre sur la sensibilité au chancre provoqué par Nectria ditissima. Ann. Sc. For., 41, (4), 77-78.

Ponchet J., Andréoli C., Blanc D., 1984. Effet de la nutrition minérale sur la réceptivité du Cyprès à Coryneum cardinale. C.R. Seminario: Il Cipresso. Malattie e difesa. Ed. C.E.C. Firenze, 20-21 oct. 1983.

Poovaiah B. W., Leopold A. C., 1976. Effects of inorganic salts on tissue permeability. Plant Physiol., 58, 182-185.
Prunier J. P., Luisetti J., Gardan L., 1973. Etude sur les bactérioses des arbres fruitiers. V. Etude du pouvoir pathogène de $P S$. mors-prunorum f. sp. persicae, agent du dépérissement bactérien du Pêcher. Méthodologie : premiers résultats sur l'influence de la date d'inoculation. Ann. Phytopathol., 5 (4), 327-346.

Prunier J. P., Gaignard J. L., Gardan L., Luisetti S., Vigouroux A., 1976. Progrès inquiétant du dépérissement bactérien dans le sud-est de la France. Arboric. fruit., 274.

Salsac L., 1977. Le potassium dans le végétal : localisation cytologique, absorption et transport, rôle physiologique. C.R. Coll. sur te potassium dans ses rapports avec la vigne et le vin. Montpellier, 4 mars 1977, $11 \mathrm{p}$

Schoenweiss D. F., 1981. The role of environmental stress in diseases of woody plants. Plant Dis., 64 (4), 308-314.

Scholander P. F., Hammel H. T., Bradstreet E. D., Hemmingsen E. A., 1965. Sap pressure in vascular plants. Science, 148, 339-346.

Simon E. W., 1978. The symptoms of calcium deficiency in plants. New Phytol., 80, 1-15.

Sinden S. L., Devay J. E., Backman P. A., 1971. Properties of syringomycin, a wide spectrum antibiotic and phytotoxin produced by Pseudomonas syringae, and its role in the bacterial canker disease of peach trees. Physiol. Plant Pathol., 1, 199-213.

Stebbins R. L., Dewey D. H., 1972. Role of transpiration and phloem transport in accumulation of 45 calcium in leaves of young apple trees. J. amer. Soc. hortic. Sci., 97 (4), 471-474.

Thomas W., Mack W. B., Fagan F. N., 1948. Foliar diagnosis : nutritional factors in relations to bacterial leaf spot of peach. Proc. am. Soc. hortic. Sci., 51, 183-190.

Turner N. C., 1981. Techniques and experimental approaches for the measurement of plant water status. Plant Soil, 58, 1339-1966.

Vigouroux A., 1968. Premières observations sur une nouvelle bactériose du Pêcher. C.R. Acad. Agric. France, 54, 1021-1026.

Vigouroux A., 1979. Incidence des basses températures sur la sensibilité du Pêcher au Dépérissement Bactérien. Ann. Phytopathol., 11 (2), 231-239.

Vigouroux A., Huguet C., 1977. Influence du substrat de culture sur la sensibilité du Pêcher au Dépérissement Bactérien. C.R. Acad. Agric. France, 63, 1095-1103.

Vigouroux A., Huguet C., 1980. Prédisposition du Pêcher au Dépérissement Bactérien sur sols d'arène et de diluvium. Ann. Phytopathol., 12 (4), 312 (note).

Vigouroux A., Huguet C., Drouhard A., Lafuste J. P., 1982. Etude de l'influence d'amendements du sol sur la sensibilité du Pêcher au Dépérissement Bactérien. C.R. Expér. 1978-1982. Groupe de travail Dépérissement Bactérien du Pêcher, Valence (26) 7 p.

Weaver D. J., Wehunt E. J., 1975. Effect of soil pH on susceptibility of peach to Pseudomonas syringae. Phytopathology, 65, 984989.

Wiebe H. J., Schatzler H. P., Kuhn W., 1977. On the movement and distribution of calcium in white cabbage in dependence of the water status. Plant soil, 48, 409-416.

Wiegand K. M., 1906. Some studies regarding the biology of buds and twigs in winter. Bot. Gaz., 41, 373-424.

Williams P. H., Keen N. T., 1967. Relation of cell permeability alteration to water congestion in cucumber angular leaf spot. Phytopathology, 57, 1378-1385. 